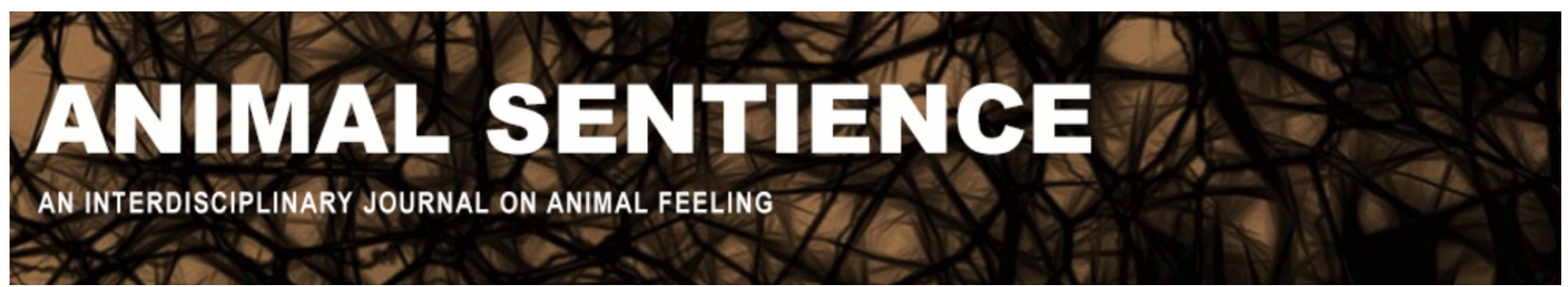

Merker, Bjorn H. (2016) The line drawn on pain still holds. Animal Sentience 3(46) DOI: $10.51291 / 2377-7478.1104$

Date of submission: 2016-03-24

Date of acceptance: 2016-03-30

(c) (i)




\title{
The line drawn on pain still holds
}

Commentary III on Key on Fish Pain

\author{
Bjorn Merker \\ Kristianstad, Sweden
}

\begin{abstract}
The many substantive criticisms raised against Key by me and by many of the other commentators will not disappear by ignoring or waving them aside with meta-discourse about anthropomorphism, just-so stories, or celestial teapots. The conceptual edifice Key inhabits and defends with such gusto may look like an impregnable fortress from the inside and Key behaves as if it were. From the outside, however, it looks more like a ramshackle structure gaping with holes and pieced together from imperfectly understood neuroscience and often faulty literature citations.
\end{abstract}

\begin{abstract}
Bjorn Merker is a neuroscientist with longstanding interest in brain mechanisms of consciousness: He has worked on subcortical mechanisms of orienting behavior in rodents and cats, mirror selfrecognition in gibbons, and structural principles intrinsic to the neural organization of a conscious state. Fjälkestadsv. 410-82, SE-29194 Kristianstad, Sweden. https://en.wikipedia.org/wiki/Björn Merker
\end{abstract}

This is my third and final commentary on Brian Key's (2016a) article "Why fish do not feel pain" and his replies to critics (Key, 2016b, 2016c), specifically to my own two previous commentaries (Merker, 2016a, 2016b). I say final, because by now it is abundantly clear that pointing out conceptual flaws and evidentiary errors in Key's arguments is to no avail when Key chooses to either ignore them altogether (as he does with most of the many specifics of both kinds raised against him in my original commentary) or adds new errors in attempted rebuttal. I pointed out such new errors in my second commentary, and in replying to it, Key now compounds them by additional ones, as follows.

Contrary to Key's insistence, a nucleus does not become a lamina by molecular and functional homology with a laminar structure, as Fig. 1 of the paper Key cites on this point (Karten, 2012) clearly shows, and its title loudly proclaims (viz. "independently of lamination"). Without a stipulation regarding "equivalent circuitry," Key's 21 criteria for feeling pain - whose grouping under four headings does not make them four, as he claims exclude birds. Perhaps the absence of this natural stipulation from Key's account relates to the fact that including it would open a cornucopia of subcortical possibilities that his conceptual commitments prevent him from exploring.

Even without such a stipulation there is nevertheless the exquisitely laminated tectum of fish to contend with. In many a species it exhibits both more laminae and a greater diversity of cell types than the mammalian neocortex (Meek, 1983; Sas and Maler, 1986; Schroeder et al., 1980; Yamamoto et al., 1999). Concerning the tectum, Key fails to correct his misreading of Yager et al. (1977). Besides the fact that it did not even address nociception but vision, 
that study did not, as Key asserts, show that tectal ablation in goldfish "does not affect escape responses to either touch or electric shock." Instead it showed, unsurprisingly, that tectal ablation abolishes visually triggered escape responses conditioned to electric shock in goldfish. Startle responses evoked by informal touching of lesioned fish with a fish net, besides being irrelevant to the issue of nociception, are easily accounted for by well-known lower brainstem startle circuitry. Blatant errors such as Key's misrepresentation of the Yager et al. study (and many others detailed in my commentaries) must be acknowledged if one wants to be taken seriously in matters of science. It is to no avail to attempt to divert the argument to a different study, not previously cited.

Similarly, Key misrepresents the issue for which I introduced the Lovejoy and Krauzlis (2010) study of 2010 in my original commentary (Merker, 2016a). I cited it, along with two other collicular studies, to specifically and explicitly counter Key's false assertion that the colliculus is limited to bottom-up processes. I did not cite it as support for a collicular role in awareness (these are different issues, after all!). Each of the three empirical papers I cited shows collicular involvement in top-down processes, contrary to Key's assertion. Moreover, on the separate issue of collicular involvement in awareness, if the non-mention of awareness in a paper concerned with other matters is evidence against collicular involvement in awareness (see Key's parentheses!), then Key will presumably allow me to cite the non-mention of awareness in Hubel and Wiesel's reports on their single-unit studies of visual cortex as evidence against cortical involvement in awareness.

Such details, however - badly though they reflect on Key's grasp of the literature and conceptual coherence - must not be allowed to hide from us the more serious matter of the many objections and criticisms Key simply ignores, such as the larger part of the substantive issues of a conceptual and evidentiary nature raised in my original commentary. Instead of engaging issue by issue with his critics - Animal Sentience is generous in its space allotment in that regard - Key typically attempts the wholesale dismissal of a critic on the grounds of some putative misconstrual of his position. In my case the occasion was provided by my simplification of Key's 21 criteria to the shorthand "neocortex" on which they are so patently modelled, down to minute details such as lamination, columnar organization, and somatosensory submodalities of "sharp versus dull pain"!

Key's inclusion of both sharp and dull pain among his criteria (i.e., Key apparently believes that there can be no capacity to feel pain unless both sharp and dull varieties are included!) bears out my contention that far from embodying theoretically well-grounded prerequisites for the experience of pain, his criteria simply detail his conception of the mammalian (human) cortical representation of nociception. Only on the basis of a doctrinal commitment to the problematic conjecture that the implementation of a conscious state is confined to cortex is such a way of proceeding even coherent. Meanwhile, that conjecture is far from being as secure as its adherents might think (see Merker, 2007, 2012, 2013), and requires one to ignore the fact that so far the strongest neural correlate of awareness has been recorded in a subcortical and not a cortical location (Wilke et al., 2009).

In conclusion, the many substantive criticisms raised against Key by me and by many other commentators will not disappear by being ignored or waved aside with meta-discourse about anthropomorphism, just-so stories, or celestial teapots. The conceptual edifice Key 
inhabits and defends with such gusto may look like an impregnable fortress from the inside and Key behaves as if it were. From the outside, however, it looks more like a ramshackle structure gaping with holes and pieced together from imperfectly understood neuroscience and often faulty literature citations (examples of both are in my original commentary). The largest of the holes is Key's utter failure to come to grips with the theoretical problem of the neural constitution of consciousness. Without a solution to that problem we cannot know for sure whether fish do in fact feel pain. Key has instead tried a shortcut via the corticocentric doctrine of consciousness, using an argument that is not even his own but originated with Rose (2002) more than a decade ago - a fact that went unmentioned in Key's article, as pointed out in the opening of my original commentary.

With that my commentaries have come full circle, and I end them by expressing the hope that Brian Key will take the requisite steps to understand the sophisticated structurefunction arrangements of the vertebrate midbrain that are so conspicuously missing from his account and so grievously misrepresented when they do enter his discourse.

\section{References}

Karten, H. (2012). Neocortical evolution: Neuronal circuits arise independently of lamination. Current Biology 23: R12-15.

Key, B. (2016a). Why fish do not feel pain. Animal Sentience 2016.003.

Key, B. (2016b). Falsifying the null hypothesis that "fish do not feel pain." Animal Sentience 2016.039.

Key, B. (2016c). Burden of proof lies with proposer of celestial teapot hypothesis. Animal Sentience 2016.079.

Lovejoy, L. P., and Krauzlis, R. J. (2010). Inactivation of primate superior colliculus impairs covert selection of signals for perceptual judgments. Nature Neuroscience 13, 261-267.

Meek, J. (1983). Functional anatomy of the tectum mesencephali of the goldfish. An explorative analysis of the functional implications of the laminar structural organization of the tectum. Brain Research Reviews, 6: 247-297.

Merker, B. (2007). Consciousness without a cerebral cortex: a challenge for neuroscience and medicine. Target article, commentaries and author's response. The Behavioral and Brain Sciences 30: 63-134.

Merker, B. (2012). From probabilities to percepts: A subcortical "global best estimate buffer" as locus of phenomenal experience. In S. Edelman, T. Fekete \& N. Zack (Eds.), Being in time: Dynamical models of phenomenal experience (pp. 37-79). Amsterdam: John Benjamins.

Merker, B. (2013). The efference cascade, consciousness, and its self: Naturalizing the first 
person pivot of action control. Frontiers in Psychology 4, article 501: 1-20.

Merker, B. (2016a). Drawing the line on pain. Animal Sentience 2016.030.

Merker, B. (2016b). How not to move the line drawn on pain. Animal Sentience 2016.064.

Rose, J. D. (2002). The neurobehavioral nature of fishes and the question of awareness and pain. Reviews in Fisheries Science, 10, 1-38.

Sas, E., and Maler, L. (1986). The optic tectum of gymnotiform teleosts Eigenmannia virescens and Apteronotus leptorhyncus: A Golgi study. Neuroscience 18: 215-246.

Schroeder, D. M., Vanegas, H., and Ebbesson, S. E. O. (1980). Cytoarchitecture of the optic tectum of the squirrelfish, Holocentrus. Journal of Comparative Neurology 191: 337-351.

Wilke, M., Mueller, K.-M., and Leopold, D. A. (2009). Neural activity in the visual thalamus reflects perceptual suppression. Proceedings of the National Academy of Sciences U.S.A. 106, 9465-9470. doi:10.1073/pnas.0900714106

Yager, D., Sharma, S. C., and Grover, B. G. (1977). Visual function in goldfish with unilateral and bilateral tectal ablation. Brain Research 137, 267-275.

Yamamoto, N., Yoshimoto M., Albert, J. S., Sawai, N., and Ito, H. (1999). Tectal fiber connections in a non-teleost actinopterygian fish, the sturgeon Acipenser. Brain Behavior and Evolution 53: 142-155. 